\title{
COVID-19 pandemic: Cleaning and disinfection - What should the radiologist know?
}

\section{Binit Sureka, Sarbesh Tiwari, Pawan Kumar Garg, Taruna Yadav, Pushpinder Singh Khera, Vibhor Tak¹, Sanjeev Misra²}

Departments of Diagnostic and Interventional Radiology, 'Microbiology and ${ }^{2}$ Director and CEO, All India Institute of Medical Sciences, Basni, Jodhpur, Rajasthan, India

Correspondence: Dr. Binit Sureka, Associate Professor, Department of Diagnostic and Interventional Radiology, All India Institute of Medical Sciences, Jodhpur - 342 005, Rajasthan, India. E-mail: binitsurekapgi@gmail.com

\section{Introduction}

The current outbreak of the novel coronavirus SARS CoV-2, epi-centred in Hubei Province of the People's Republic of China, has spread to many other countries. On $30^{\text {th }}$ January 2020, the WHO Emergency Committee declared a global health emergency based on the growing case notification rates at Chinese and international locations. As of $3^{\text {rd }}$ May 2020, the Ministry of Health and Family Welfare have confirmed a total of 26535 cases and 1223 deaths in the country since its first case on $30^{\text {th }}$ January.

Cleaning and disinfecting activities in hospitals are critical for preventing healthcare-associated infections. The purpose of this article is to consider the effects of COVID-19 on the imaging equipment, with particular consideration from the guidelines currently available from the Centers for Disease Control and Prevention, Ministry of Health and Family Welfare that may be applicable to radiology. ${ }^{[1]}$ General principles to be followed while cleaning and disinfecting the radiology facilities and equipment are listed in Table 1. Various chemical disinfectants available in the market are highlighted in Table 2 and Figures 1, 2.

\section{Cleaning and Disinfection of Radiology Department ${ }^{[2-4]}$}

- Radiology reporting rooms, office spaces, waiting areas and conference rooms should be cleaned every evening after office hours or early in the morning before the rooms are occupied

- If contact surface is visibly dirty, it should be cleaned with soap and water prior to disinfection. Prior to cleaning, the worker should wear disposable rubber boots, gloves (heavy duty), and a triple layer mask

- All indoor areas should be mopped with a disinfectant with $1 \%$ sodium hypochlorite or phenolic disinfectants
- High contact surfaces such as elevator buttons, handrails/handles and call buttons, public counters, intercom systems, equipment like telephone, printers/scanners and other office machines should be cleaned at least 3-4 times daily by with a linen/absorbable cloth soaked in $1 \%$ sodium hypochlorite. Guidelines for preparation of $1 \%$ sodium hypochlorite are in Table 3

- Frequently touched areas like table tops, chair handles, pens, diary files, keyboards, mouse, mouse pad, tea/coffee dispensing machines etc., should specially be cleaned

- Barrier protective coverings (e.g., clear plastic wraps) can be used for surfaces particularly those that are difficult to clean

- For metallic surfaces like door handles, security locks, keys etc., $70 \%$ alcohol can be used to wipe down surfaces where the use of bleach is not suitable

- Hand sanitizing stations should be installed in office premises (especially at the entry) and near high contact surfaces.

\section{Cleaning and Disinfection of Radiology Equipment}

General mandatory principles for cleaning and disinfecting radiology equipment are listed in Table 1.

X-ray equipment

Parts: Main equipment, touch user interface, monitors, keyboard, liquid crystal displays (LCD) and detector.

Cover - Wrap the X-ray machine, image receptor and anatomical marker with disposable two-layer double-bagged fluid-impermeable plastic material. The detector should be wrapped in a disposable single-use water impermeable plastic bag and ideally this plastic bag should be changed after every patient.

Cleaning - Only use water or a lukewarm diluted household cleaning agent solution. The use of other than the 


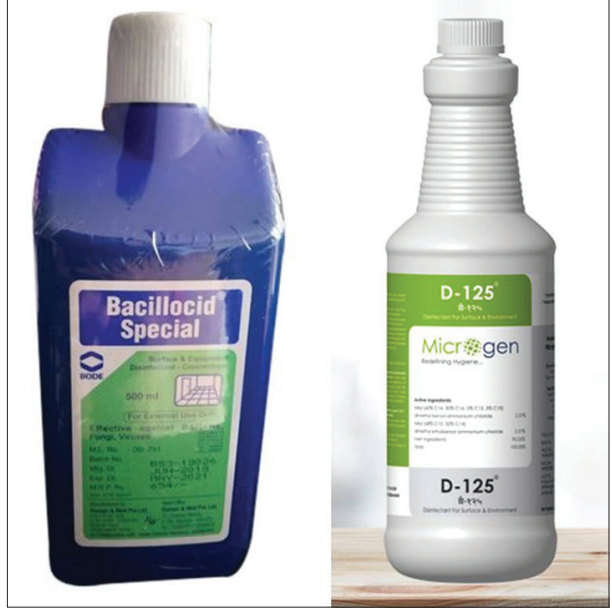

Figure 1: Chemicals used in cleaning and disinfection

Table 1: General principles to be followed for cleaning and disinfection

1. Wear proper personal protective equipment (PPE) - triple-layer surgical mask, disposable gown, heavy duty gloves, shoe cover, cap and face shield/ goggles while cleaning.

2. Always switch the system off at the main power before cleaning.

3. Follow manufacturer's instructions for cleaning. Never mix household bleach with ammonia or any other cleanser.

4. X-ray and ultrasound systems should be covered with two-layer of fluid impermeable plastic if fogging is being done.

5 . Alcohol solutions should contain $\leq 70 \%$ alcohol.

6 . Do not shake dirty laundry.

7. Wash hands with soap and water after removal of gloves.

8. If soap and water are not available and hands are not visibly dirty, an alcohol-based hand sanitizer that contains at least $60 \%$ alcohol may be used. 9. While disinfecting facilities, care should be taken to ensure that the discharge of the vapours is sufficiently removed from the windows. Air must not be recirculated. Ensure ten air exchanges per hour.

10. Install exhaust ventilation systems in ultrasound and $x$-ray rooms.

11. The air-conditioning units should be switched off during the cleaning process.

12. Seal the equipment room with tape and plastic covering doors and vents during cleaning.

13. Downtime of at least 30-60 minutes is required after disinfection.

14. All instructions in the operator manual regarding cleaning and disinfection must be always observed.

15. Read all the instructions written on each disinfectant and cleansing bottle carefully before using.

recommended cleaning agents can result in damage in the equipment. Wipe machine parts with a moist cloth (squeeze out wet cloth before using it) until all contaminations are removed. Remove any watery residues immediately. The back of the X-ray detector should be cleaned first so that it has more time to dry while the front is being cleaned. Appropriate cleaning wipes with vendor-approved disinfectants must be used to clean the detector at least twice daily.

Disinfection - Since the radiography equipment is a non-critical medical device, and also the equipment is wrapped in a cover, it does not require disinfection. However, when there is hazardous spill on the equipment,

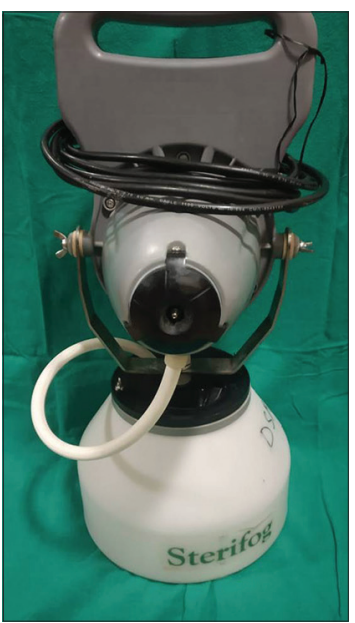

Figure 2: Sterifog Fogging machine

disinfection may be required. To disinfect surfaces, aldehyde solutions, guanidine derivatives and peroxide compounds should be used. Alcohol-based products should not be used for surface cleaning. After disinfection, wipe the system with a dry soft cloth or let the system dry naturally. Sterilisation is not allowed for X-ray equipment.

\section{Ultrasound}

Parts: Transducer, console, liquid crystal displays (LCD), touch user interface, monitors and keyboard

Precautions:

1. Do not clean the system with chlorinated or aromatic solvents such as isopropyl alcohol

2. Do not use spray cleaners on the ultrasound as it may damage the internal components

3. Do not pour fluid on the ultrasound system

4. Disconnect transducers from the main system before cleaning

5. Take extra precautions to clean trackball, touchpad, keys, knobs and side controls

6. Ensure fluid does not seep into the openings of system.

Critical item: Ultrasound probe used in sterile body cavities (intraoperative) - should be sterilised using glutaraldehyde or hydrogen peroxide.

Semi critical item: Endocavitory probes - should be treated with high-level disinfectant like glutaraldehyde, hydrogen peroxide, ortho-phthalaldehyde, and peracetic acid with hydrogen peroxide.

Noncritical item: probes used in intact skin - should be treated with low-level disinfectant.

Cleaning the transducer: Dip the transducer (not cable) in clean water or soap water to remove all foreign material or wipe the transducer with moist sponge. Avoid using a brush. Dry the transducer with a clean cloth. 
Table 2: List of chemical agents for cleaning and disinfection ${ }^{[2-4]}$

\begin{tabular}{|c|c|c|}
\hline Cleaning agents & Purpose and mechanism of action & Options \\
\hline $\begin{array}{l}\text { Aldehyde (high-level } \\
\text { disinfectant) }\end{array}$ & $\begin{array}{l}\text { Glutaraldehyde (1.0-1.5\%) - excellent disinfective qualities against } \\
\text { all bacteria, bacterial spores and viruses. The biocidal activity of } \\
\text { glutaraldehyde results from its alkylation of sulfhydryl, hydroxyl, } \\
\text { carboxyl, and amino groups of microorganisms, which alters RNA, } \\
\text { DNA and protein synthesis. }\end{array}$ & $\begin{array}{l}\text { Formaldehyde, paraformaldehyde, glutaraldehyde, calgocide } \\
14 \text {, cidex and vespore }\end{array}$ \\
\hline $\begin{array}{l}\text { Quaternary compounds } \\
\text { (Available as both } \\
\text { high- and low-level } \\
\text { disinfectant) }\end{array}$ & $\begin{array}{l}\text { The bactericidal action of the quaternaries has been attributed } \\
\text { to the inactivation of energy-producing enzymes, denaturation of } \\
\text { essential cell proteins and disruption of the cell membrane. Their } \\
\text { effectiveness and safety increase when they are combined with } \\
\text { other disinfecting agents. They are not effective against hydrophilic } \\
\text { viruses but are effective against lipophilic viruses. }\end{array}$ & $\begin{array}{l}\text { Alkyl dimethyl benzyl ammonium chloride, alkyl dimethyl } \\
\text { ethylbenzyl ammonium chloride, benzyl alkyl dimethyl } \\
\text { ammonium chloride, didecyl dimethyl ammonium chloride, } \\
\text { dioctyl dimethyl ammonium chloride, N-alkyl dimethyl benzyl } \\
\text { ammonium chloride, octyldecyldimethylammonium chloride } \\
\text { and quaternary ammonium chloride }\end{array}$ \\
\hline Alcohol (Intermediate) & The most feasible explanation for the antimicrobial action of alcohol & 70\% ethyl alcohol Isopropyl \\
\hline
\end{tabular}

Chlorine derivatives The germicidal action has been attributed to oxidation of sulfhydryl (High-level disinfectant) enzymes and amino acids; ring chlorination of amino acids; loss of intracellular contents; decreased uptake of nutrients; inhibition of protein synthesis; decreased oxygen uptake; oxidation of respiratory components; decreased adenosine triphosphate production; breaks in DNA; and depressed DNA synthesis

Benzene (High-level disinfectant) Interact with amino acids, proteins, and microorganisms. These chemicals kill spores by blocking the spore germination process.

Alkylamines

Also referred as aliphatic amines. New category of germicidals effective against fatty acids.

Phenol derivatives (0.5-3\%) (Low-level disinfectant)

In high concentrations, phenol acts as a gross protoplasmic poison, penetrating and disrupting the cell wall and precipitating the cell proteins. Low concentrations of phenol and higher molecular-weight phenol derivatives cause bacterial death by inactivation of essential enzyme systems and leakage of essential metabolites from the cell wall. Usually they are black or white fluids.

Organic acids

Function similarly to other oxidizing agents-that is, it denatures

(High-level disinfectant) proteins, disrupts the cell wall permeability and oxidizes sulfhydryl and sulphur bonds in proteins, enzymes and other metabolites.

Peroxide compounds (High-level disinfectant)

Peroxide compound works by producing destructive hydroxyl-free radicals that can attack membrane lipids, DNA, and other essential cell components. Hydrogen peroxide is active against a wide range of microorganisms, including bacteria, yeasts, fungi, viruses and spores

Guanidine compounds Bactericidal and fungicidal

NaDCC (Sodium dichloroisocyanurate). Sodium hypochlorite ('bleach'). Calcium hypochlorite Chlorine products are available as liquids or solid powders. The strength of a chlorine solution is expressed in ppm of free chlorine. Disadvantages of hypochlorite include corrosiveness to metals in high concentrations (>500 ppm), discolouring of fabrics.

Ortho-phthalaldehyde (OPA)

Monoethanolamine and triethanolamine

Ortho-phenylphenol, ortho-benzyl-para-chlorophenol, amphyl, staphene, hexachlorophene - Phisohex, chlorhexidine - Hibistat, Hiblicens and Lysol

Peracetic acid, carboxylic acid and acetic acid

Hydrogen peroxide $(3.0-6.0 \%)$

Polyhexamethylene guanidine (PHMG)

Table 3: Guidelines for Preparation of $1 \%$ sodium hypochlorite solution ${ }^{[2]}$

\begin{tabular}{lcc}
\hline Product & Available chlorine & $1 \%$ hypochlorite (10000 chlorine ppm) \\
\hline Sodium hypochlorite - liquid bleach & $3.5 \%$ & 1 part bleach to 2.5 parts water \\
Sodium hypochlorite - liquid & $5 \%$ & 1 part bleach to 4 parts water \\
NaDCC (sodium dichloroisocyanurate) powder & $60 \%$ & 17 grams to 1 litre water \\
NaDCC (1.5 g/tablet) - tablets & $60 \%$ & 11 tablets to 1 litre water \\
Chloramine - powder & $25 \%$ & $80 \mathrm{~g}$ to 1 litre water \\
Bleaching powder & $70 \%$ & $7 \mathrm{~g}$ to 1 litre water \\
\hline
\end{tabular}

$5 \%$ sodium hypochlorite: 50000 chlorine ppm; $1 \%$ hypochlorite: 10000 chlorine ppm; $0.5 \%$ hypochlorite: 5000 chlorine ppm

Disinfecting the transducer: Immerse the transducer (not cable) into a solution ( $22 \%$ hydrogen peroxide or $4.5 \%$ peroxyacetic acid or $2.4 \%$ glutaraldehyde) for 10-12 hours. After this, rinse the transducer with water to remove all chemical residues. Wipe off the water with sterile cloth after this.

Probes used only for external use (linear, curvilinear and phased array transducers) on intact skin without contamination of blood or bodily fluids should be cleaned with low-level disinfection (soap water, quaternary ammonia wipes) between each use. ${ }^{[5]}$

Probes used externally for percutaneous procedures (vascular access, thoracentesis, paracentesis, arthrocentesis, pericardiocentesis, lumbar puncture, regional anaesthesia and other procedures) should be covered with single-use protective covers and sterile gel applied. They should subsequently be cleaned with low-level disinfection. 
Probes used internally on mucous membranes and internal orifices ((endocavitory probe for intraoral procedures/ transvaginal examinations and transesophageal probes) should be covered with high-quality single-use probe covers during each examination, followed by high-level disinfection between each use. An alternative procedure for disinfecting the endocavitory probes involves: ${ }^{[6]}$

- Removing the gel from the transducer

- Cleaning the transducer with soap and water

- Wiping the transducer with $70 \%$ alcohol or soak it for 2 minutes in 500 ppm chlorine

- Rinsing with tap water

- Air drying and wiping with cloth.

\section{Computed tomography (CT) scanner system}

Parts: Gantry - gantry cover, operator panel, touch panel; Patient table - patient table, mattress; monitor; other components - positioning aids, body straps, ECG cables, foot switch.

Gantry - Before starting the cleaning process, the gantry should be switched off. Remove all impurities like blood and contrast with damp cloth. Cleaning agents and disinfectants recommended for gantry cover, operating panel and touch panel are surgical spirit, alcohol $(\leq 70 \%)$, aldehyde, quaternary compounds, guanidine derivatives, pyridine derivatives, chlorine derivatives, benzene, alkylamines, organic acids and peroxide compounds. For the touch panel in the gantry system, use an anti-static cleaner, alcohol-free glass cleaning fluid or a solution of water and a $\mathrm{pH}$-neutral cleaning agent. Paper towels are not recommended as these fibrous materials can scratch the screen. Corrosive agents should be avoided as it can damage the surface coating.

Patient table - All chemicals used for cleaning gantry can be used for cleaning the patient table. Mattress should always be covered with plastic sheet for maintaining hygiene. Cleaning agents and disinfectants recommended for mattress are $\mathrm{pH}$-neutral agents, guanidine derivatives, chlorine derivatives and alkylamines. Soft brush may be used for regular cleaning. Mattress should not be cleaned with surgical spirit as this may lead to wrinkling. Alcohols and aldehydes should not be used for cleaning mattress.

Monitor - Ensure monitor is switched off before cleaning. Clean the monitor with damp cloth. Only an antistatic cleaner should be used for cleaning the monitor screen. The monitor housing can be cleaned with same materials as used for gantry and surgical spirit should be avoided.

Other components - Patient positioning aids made of foam material and body straps can be cleaned by using pH-neutral agents, guanidine derivatives, chlorine derivatives and alkylamines. Alcohol $(\leq 70 \%)$ can be used for cleaning ECG cables.
Disinfection: Spray machine for fogging is not recommended for CT scanner. It should be applied only on floor. Normally technicians/end users never wipe the equipment surface after fumigation, which is the reason for not recommending fumigation.

Bacillocid rasant is a newer and effective compound in environmental decontamination with good cost benefits, good material compatibility, excellent cleaning properties and virtually no residues. It has the advantage of being a formaldehyde-free disinfectant cleaner with low use concentration, provides complete asepsis within 30 to 60 minutes.

Air disinfection - Air exchange of minimum fresh air volume of $3 \mathrm{cum} /$ hour/person and $3.75 \mathrm{cum} /$ hour/sqm is recommended. The recommendation is to maximize supply of outside air within the limits of the system. In buildings without mechanical ventilation systems, it is recommended to actively use operable windows. Installation of UVGI (Ultraviolet germicidal irradiation) for larger ducted units and AHUs to keep coils continuously clean and disinfected is highly recommended. It is advisable to regularly inspect the AHUs and ducts for air tightness and low leakage. Minimum air changes of around 10-15 ACHP (air changes per hour) is advised for good ventilation. The mechanical exhaust air should have $70 \%$ to $80 \%$ of fresh air. In case of recirculating system, it is recommended to limit return air circulation. Air steriliser or ultraviolet lamp disinfection is being recommended for air disinfection at least 4 times/day. It does not damage electronic or cable components inside the gantry. Low-pressure mercury $(\mathrm{Hg})$ discharge lamps are commonly used in ultraviolet germicidal irradiation (UVGI) applications which emit shortwave ultraviolet-C (UV-C, 100-280 nanometer) radiation, primarily at $254 \mathrm{~nm}$. UV-C radiation kills or inactivates microbes by damaging their deoxyribonucleic acid (DNA). Research has shown that UV-C light has been effective in altering the cell structure and exposure to UV-C light of $254 \mathrm{~nm}$ for a period of 20-30 minutes and is effective in deactivating the virus. Usage of ozone and hydrogen peroxide is no longer recommended for air disinfection. ${ }^{[7]}$

Magnetic resonance imaging (MRI)

Follow the manufacturer's instructions and use only approved disinfectants and cleaning agents. Always use a damp cloth for cleaning. Do not pour chemicals in the scanner.

Cleaning patient table, straps, plugs and connectors: Approved agents are aldehydes, quaternary compounds, guanidine derivatives, peroxide compounds, pyridine derivatives, chlorine derivatives, alkylamines, organic acids and commercially available detergents. Benzene, acetone and alcohol solutions are not recommended. 
Receptors: All the chemicals mentioned above can be used for cleaning except chemicals containing alcohol and ethers.

LCD monitors and video display: Ideally should be cleaned thoroughly once every two months. Use commercially available window cleaners in diluted form.

Camera lens, data carrier: Use dry cotton or microfiber cloth for cleaning.

\section{Mammography}

Parts: Compression plates, biopsy unit, object table, patient handles and face shield.

All parts of the unit which come into contact with the patient must be cleaned prior to examination. The plastic trays can be removed from the holder to simplify cleaning.

Wipe the system with a damp, lint-free, non-woven cloth or sponge. Moisten the cloth only with water or lukewarm, diluted and aqueous solution using a household cleanser without abrasives. Anaesthetics and skin disinfectants used during biopsies can damage or discolour the plastic parts of the compression plates. If such substances get onto the compression plates, wipe these off immediately with a moist cloth.

Compression troughs and holders should be disinfected by quaternary ammonium compounds. Alcohol-based products should not be used. Disinfectants based on substituted phenols and chlorine-splitting compounds have a slightly corrosive effect and therefore are not recommended generally.

\section{Hospital policies for disinfection}

It is the responsibility of radiology departments, in collaboration with hospital infection control committee and Medical Superintendent Office, to establish policies for disinfecting radiology equipment to manage infection risk. In addition, radiology departments should check with their equipment vendors to determine which disinfectants are safe for radiology equipment. There should be clear cut written SOPs in Radiology Department regarding (i) when to disinfect the facility, (ii) the personnel who will be involved in cleaning, (iii) the specific agents to be used and (iv) the radiologist designated for monitoring and ensuring the disinfection and cleaning.

\section{Conclusion}

In summary, in this war against COVID-19 pandemic, we have to triage patients for appointment, standardise our protocols for imaging and assure technicians and cleaning staff are adequately trained for disinfection and cleaning of equipment as well as the facility. In short, the objects should be disinfected with $1000 \mathrm{mg} / \mathrm{L}$ chlorine containing disinfectant once every 4 hours, equipment be disinfected as mentioned in equipment manuals twice a day, air and environment disinfection using air sterilizer or ultraviolet lamp 4 times/day and ground disinfection by $1000 \mathrm{mg} / \mathrm{L}$ chlorine containing disinfectant once every 4 hours. A combination of deep cleaning with surface disinfectants and ultraviolet light is the key for the radiologists to prepare themselves in fighting this COVID-19 pandemic. Guidelines are changing and this is not a static document. COVID-19 is a newly discovered virus; the guidelines are evolving so the disinfection policies need to be reviewed on a periodic basis.

\section{References}

1. Centres for Disease Control. [Internet]. Available from: https://www. cdc.gov/infectioncontrol/pdf/guidelines/disinfection-guidelines- $\mathrm{H}$. pdf. [Last cited on 2020 May 03].

2. Ministry of Health and Family Welfare [Internet]. Available from: https://www.mohfw.gov.in/pdf/Guidelinesondis infectionofcommonpublicplacesincludingoffices.pdf. [Last cited on 2020 May 03].

3. Internet. Available from: https://www.brainscape.com/flashcards/ test-5-disinfectants-alcohols-and-aldehyd-5546999/packs/8036648. [Last cited on 2020 May 03].

4. Vikaspedia [Internet]. Available from: https://vikaspedia.in/ health/sanitation-and-hygiene/swachhta_abhiyaan_guidelines/ hospital-cleaning-products-machines-procedures. [Last cited on 2020 May 03].

5. Guideline for Ultrasound Transducer Cleaning and Disinfection. Ann Emerg Med 2018;72:e45-7. doi: 10.1016/j.annemergmed. 2018.07.035. PubMed PMID: 30236343.

6. Garland SM, de Crespigny L. Prevention of infection in obstetrical and gynaecological ultrasound practice. Aust N Z J Obstet Gynaecol 1996;36:392-5.

7. Dexter F, Parra MC, Brown JR, Loftus RW. Perioperative COVID-19 Defense: An evidence-based approach for optimization of infection control and operating room management [published online ahead of print, 2020 Mar 26]. Anesth Analg 2020;10.1213/ ANE.0000000000004829. doi: 10.1213/ANE.0000000000004829.

This is an open access journal, and articles are distributed under the terms of the Creative Commons Attribution-NonCommercial-ShareAlike 4.0 License, which allows others to remix, tweak, and build upon the work non-commercially, as long as appropriate credit is given and the new creations are licensed under the identical terms.

\begin{tabular}{|l|l|}
\hline \multicolumn{2}{|c|}{ Access this article online } \\
\hline Quick Response Code: & \\
\hline & Website: \\
\hline & www.iji.org \\
\cline { 3 - 4 } & \\
\hline
\end{tabular}

Cite this article as: Sureka B, Tiwari S, Garg PK, Yadav T, Khera PS, Tak V, et al. COVID-19 pandemic: Cleaning and disinfection - What should the radiologist know? Indian J Radiol Imaging 2021;31:S207-11.

Received: 06-May-2020 Revised: 28-May-2020 Accepted: 17-Jul-2020 Published: 23-Jan-2021 